\title{
Overview of macroautophagy regulation in mammalian cells
}

\author{
Maryam Mehrpour ${ }^{1,2}$, Audrey Esclatine $e^{1,2}$, Isabelle Beau ${ }^{1,2}$, Patrice Codogno ${ }^{1,2}$

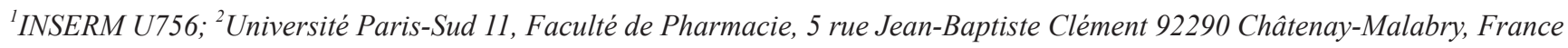

\begin{abstract}
Macroautophagy is a multistep, vacuolar, degradation pathway terminating in the lysosomal compartment, and it is of fundamental importance in tissue homeostasis. In this review, we consider macroautophagy in the light of recent advances in our understanding of the formation of autophagosomes, which are double-membrane-bound vacuoles that sequester cytoplasmic cargos and deliver them to lysosomes. In most cases, this final step is preceded by a maturation step during which autophagosomes interact with the endocytic pathway. The discovery of AuTophaGyrelated genes has greatly increased our knowledge about the mechanism responsible for autophagosome formation, and there has also been progress in the understanding of molecular aspects of autophagosome maturation. Finally, the regulation of autophagy is now better understood because of the discovery that the activity of Atg complexes is targeted by protein kinases, and owing to the importance of nuclear regulation via transcription factors in regulating the expression of autophagy genes.
\end{abstract}

Keywords: autophagy; cell signaling; intracellular trafficking; lysosomes; proteolysis

Cell Research (2010) 20:748-762. doi:10.1038/cr.2010.82; published online 15 June 2010

\section{Introduction}

Macroautophagy (referred to simply as "autophagy" below) is a homeostatic "self-eating" process that has been conserved among eukaryotic cells, and which involves the digestion of cytoplasmic components via the lysosomal pathway [1]. Under normal conditions, it allows cells to break down long-lived proteins, thus complementing the action of the proteasome, which deals with short-lived proteins. During periods of starvation, stimulation of autophagy is important to provide cells exposed to nutrient deprivation with amino acids and fatty acids to maintain metabolism and ATP levels compatible with cell survival. For example, it has been shown that the stimulation of autophagy plays a critical role in counteracting nutrient deprivation following birth in newborn mice [2]. Under basal conditions, autophagy helps the cell to get rid of damaged organelles, such as mitochondria and toxic aggregation-prone proteins [3]. The functions of autophagy are not limited to these aspects, but extend beyond, as shown by the discovery of its role in the innate and adaptive immune responses (reviewed in [4]). Autophagy malfunction contributes to

Correspondence: Patrice Codogno

Tel: +33146835720; Fax: +33146835537

E-mail: patrice.codogno@u-psud.fr the pathogenesis of a variety of diseases, including cancer, neurodegenerative and cardiovascular disorders, and infectious diseases (reviewed in [5]). Another important aspect of autophagy in mammalian cells that remains to be unraveled is the role of autophagy in cell death, which has been the topic of several recent reviews [6-8].

During autophagy, part of the cytoplasm containing long-lived proteins or organelles is surrounded by a cisternal membrane, designated the phagophore by Seglen [9] (Figure 1). The term "isolation membrane" is also used as a synonym of phagophore. The phagophore then closes to form a double-membraned vacuole, known as the autophagosome. Autophagosomes use dynein motors to move along microtubules towards the microtubuleorganizing center, where they fuse with lysosomes to form autolysosomes. However, most of the autophagosomes receive input from the endocytic compartments before they fuse with lysosomes (reviewed in [10-12]). Many of the AuTophaGy-related (ATG) genes that have been identified in yeast by genetic screens (more than 30) have mammalian counterparts, and 18 different Atg proteins are known to be recruited to the isolation membrane, where they are involved in autophagosome formation [13]. The origin of the membranes involved in autophagosome formation is not known with certainty, but new findings suggest that the endoplasmic reticulum (ER) may be the source of the lipids in the autophagosomal 


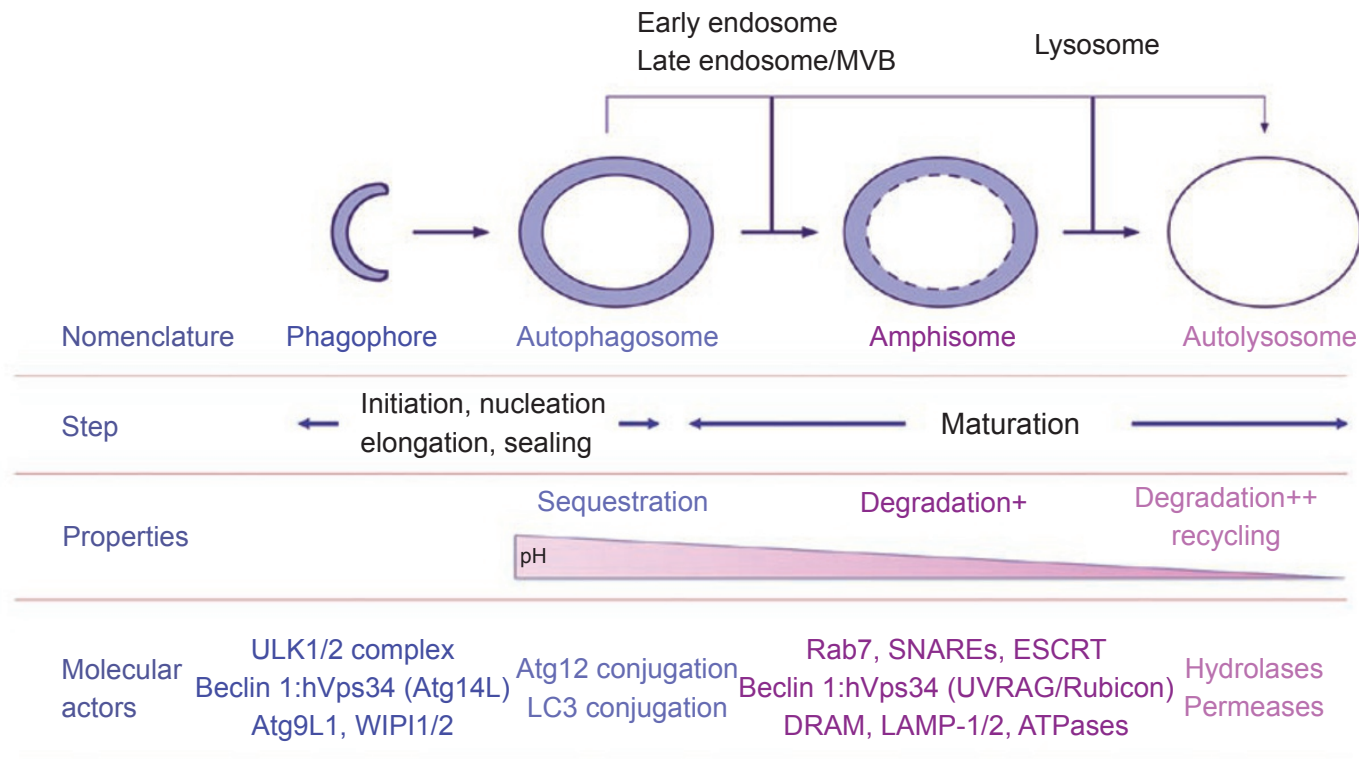

Cytoskeleton Microtubules and MAPs, intermediate filaments (?), actin filaments (?)

Figure 1 Integrated view of mammalian autophagy. Autophagy is initiated by the nucleation of an isolation membrane or phagophore. This membrane then elongates and closes on itself to form an autophagosome. During starvation, the process is initiated by the ULK1/2 complex, the activity of which is controlled by the mTORC1 complex. The Beclin 1:hVps34:Atg14L complex, Atg9L1 and WIPI proteins (human orthologs of the yeast Atg18) contribute to the nucleation of the phagophore. Elongation of the phagophore membrane is dependent on the Atg12 and LC3 conjugation systems. Closure of the autophagosome is dependent on the activity of the LC3-conjugation system. In most cases, once formed the autophagosome receives input from the endocytic pathway (early, late endosomes and multivesicular bodies (MVBs)). These steps are collectively termed maturation. The amphisome resulting from these fusion processes is more acidic than the autophagosome, and acquires hydrolytic enzymes. The different actors involved at this stage are also involved in the intracellular trafficking in the endocytic pathway (Rab7, SNARES and ESCRT). LAMP-1/2 and ATPases are membrane constituents of the endolysosomal compartment. The DRAM protein is a lysosomal membrane protein. The Beclin 1:hVps34:UVRAG complex positively regulates the maturation of autophagosomes. When associated with the protein Rubicon, it down-regulates autophagosome maturation. Note that Beclin 1 forms a part of complexes that control both the formation and maturation of autophagosomes. Because of their implication in the formation and maturation of autophagosomes, microtubules, as well as microtubule-associated proteins (MAPs), are shown. It has been suggested that intermediate and actin filaments may be involved in the early stages of autophagy.

membranes. Ktistakis and colleagues [14] propose that autophagosomes are formed in a high-phosphatidylinositol 3-phosphate (PtdIns 3P), cup-shaped compartment known as the "omegasome" (from its omega-like shape), which is dynamically connected to the ER. Recent electron tomography analyses have demonstrated a direct connection between the ER and the phagophore $[15,16]$.

The goal of this review is to provide an overview of recent advances in our understanding of autophagy and its regulation pathways. We have decided to divide the regulation of autophagy into three successive levels, even though the boundaries between them are not clear cut. The first level of regulation is defined as that during which autophagosomes are formed. The second corresponds to the late stage of autophagy (maturation and fusion with the lysosomal compartment), and the third to several signaling pathways that relay various stresses and stimuli to the autophagy machinery.

\section{Autophagosome formation}

\section{Autophagosome initiation}

Autophagosome initiation and formation in yeast is centrally controlled by the Atg1:Atg13:Atg17 complex [17]. It has recently been shown that the mammalian counterpart of this complex is ULK:Atg13:FIP200 (200$\mathrm{kDa}$ focal adhesion kinase family-interacting protein) [18-20]. The two mammalian homologues of serine/threonine protein kinase Atg1, unc-51-like kinase-1 (ULK1) and -2 (ULK2), and the homolog of Atg17, FIP200, interact with mammalian Atg13 to form a stable complex, which is located at the phagophore during starvation. 
mTOR (mammalian Target of Rapamycin) complex 1 (mTORC1), which contains mTOR kinase, is a central inhibitor of autophagy, and it interacts with both ULK1 and ULK2 and inactivates them by phosphorylation (see below). Recent evidence suggests that the structure and function of the ULK:Atg13:FIP200 complex in mammals differ from those of the equivalent Atg1 complex in yeast. The ULK:Atg13:FIP200 complex is a stable complex that is not regulated by nutrition conditions. Inactivation of mTOR by starvation or rapamycin activates ULKs and results in phosphorylation of Atg13 and FIP200. This differs from what is observed in yeast, where the inactivation of TOR increases the binding affinity of Atg1 to Atg13 and Atg17 [13]. Moreover, a novel mammalian Atg13-binding protein, Atg101, which is not conserved in Saccharomyces cerevisiae, has been identified by two teams simultaneously [21, 22]. Atg 101 is essential for autophagy; it localizes to the phagophore and stabilizes the expression of Atg13. The interaction between Atg101 and the ULK:Atg13:FIP200 complex is stable, regardless of the nutritional conditions.

The nucleation and assembly of the initial phagophore membrane is dependent on the class III phosphatidylinositol 3-kinase (PI3K) complex. This complex consists of classIII PI3K or hVps34 (hereafter referred to as hVps34), its regulatory protein kinase $\mathrm{p} 150$ or $\mathrm{hVps} 15$, Beclin 1 (Atg6 in yeast), and the recently discovered mammalian homolog of Atg14, known as Atg14L or Barkor (Beclin 1-associated ATG key regulator) $[23,24]$. The activity of this complex is tightly controlled by positive and negative regulators (see below). For the sake of clarity, hVps15 is not represented here in Beclin 1:hVps34 complexes. PtdIns3P is generated by $\mathrm{hVps} 34$, and is important for subsequent events that lead to the formation of autophagosomes. Several up-regulating factors, such as VMP1 (Vacuole membrane protein 1), AMBRA1 (Activating molecule in Beclin 1-regulated autophagy), MyD88 (myeloid differentiation factor 88), and down-regulators, such as the proteins of the Bcl-2 family, control the production of PtdIns3P by the Beclin 1:hVps34:Atg14L complex [12, 25, 26]. Moreover, members of the myotubularin phosphoinositide 3-phosphatase family regulate the initiation of autophagy by degrading PtdIns3P [27]. One unresolved question is how the ULK:Atg13:FIP200 and Beclin $1: \mathrm{hVps} 34: \operatorname{Atg} 14 \mathrm{~L}$ complexes are interconnected in the regulation of autophagy.

\section{Membrane flow during autophagosome formation}

The level of PtdIns3P as a membrane component of the elongating phagophore is greatly increased [14]. In yeast, PtdIns3P recruits the Atg18:Atg2 complex to autophagic membranes through an Atg18-PtdIns3P inter- action. In mammalian cells, WIPI-1/2, which belong to the human WIPI family of phospholipid-binding effectors, are homologs of Atg18, and function as a PtdIns3P scaffold in the early stages of autophagy [28]. Although there is a mammalian homolog of Atg2, its function in autophagy remains to be elucidated (Tassula ProikasCezanne, personal communication).

Atg9 and its mammalian ortholog (mAtg9 or Atg9L1) are the only transmembrane Atg proteins. Under normal conditions, Atg9L1 traffics between the trans-Golgi network (TGN) and late endosomes [29]. In response to starvation, Atg9L1 is found in a peripheral pool, where it co-localizes with MAP-LC3 or LC3 (microtubuleassociated protein light chain 3) and Rab7, which are both markers of autophagic vacuoles (see below). The trafficking of Atg9L1 is dependent on the p38 $\alpha$ mitogenactivated protein kinase and its binding protein p38IP [30]. The putative role of Atg9L1 is to carry lipids and/or serve as a platform for recruiting effectors to the phagophore (reviewed in [31]).

\section{Phagophore elongation}

The Beclin 1:hVps34:Atg14L complex and other Atg proteins recruit the Atg12-Atg5:Atg16L multimeric complex and the lipidated form of LC3 [32-34]. These last two constituents, which are essential for the forming autophagosome to expand, act sequentially, and result from two ubiquitin-like conjugation systems [13]. The conjugation of Atg12 to Atg5 normally occurs soon after the individual proteins have been synthesized. Atg12 is activated by $\operatorname{Atg} 7$ (homologous to the E1 ubiquitin-activating enzyme) and then conjugated to Atg5 by Atg10 (homologous to the E2 ubiquitin-conjugating enzyme). LC3 is first cleaved by a protease, Atg4 (the Atg4 family is composed of four members, Atg4A-D; Atg4B cleaves LC3 with the highest efficiency), leaving a glycine residue at the $\mathrm{C}$ terminus. In response to the induction of autophagy, the $\mathrm{C}$ terminus of $\mathrm{LC} 3$ is conjugated to the polar head of phosphatidylethanolamine (PE), a component of the phospholipid bilayer, in a reaction that requires Atg7 (E1-like), Atg3 (E2-like) and the Atg12-Atg5:Atg16L complex (E3-like). The lipidated form of LC3 is associated with the outer and the inner membranes of the autophagosome, whereas unconjugated LC3 is cytosolic, and is the major form of LC3 present under normal conditions. The human LC3 family is composed of three members, LC3A-C, plus the LC3 paralogs GATE-16, GABARAP1, 3 and Atg8L. LC3B has the widest specificity, but the roles of the other LC3-related proteins remain to be identified.

When the autophagosome is formed, the Atg12Atg5:Atg16L complex leaves the autophagosome, and 
the pool of LC3 associated with the autophagosomal cytosolic surfaces is cleaved from the PE by the protease Atg 4 and recycled. The location of the Atg16L complex at the phagophore dictates the location of the LC3-conjugation reaction [35]. It has been suggested that the localization of the Atg16L complex on the membrane may be dependent on the monomeric GTPase Rab33B [36]. Interestingly, another Rab protein, Rab5, has been shown to regulate the conjugation of $\operatorname{Atg} 12$ at the phagophore through hVsp34 [37].

\section{Alternatives to the classical autophagosome formation}

Recently, non-canonical forms of autophagy, in which only a part of the repertoire of Atg proteins is used to form a functional autophagosome, have been described. This probably reflects the complexity and plasticity of the autophagic process. Interestingly, in a non-canonical form of autophagy that is independent of Atg5 and Atg7, the Rab9 protein, which is located on the TGN and endosomal membranes, is involved in autophagosome formation [38]. Another form of autophagy independent of Beclin 1 and hVps34 but dependent on Atg5 and Atg7 has been reported in cancer cells exposed to resveratrol, neurons exposed to a neurotoxin and $\mathrm{CHO}$ cells exposed to the $\alpha$-hemolysin of $S$. aureus [39-41]. In both forms of non-canonical autophagy, ULK is required to initiate autophagosome formation ([38], Tassula Proikas-Cezanne and Patrice Codogno, unpublished results). Although $\alpha$-hemolysin-induced autophagosomes cannot mature [39], the maturation of autophagosomes and degradation of cargo have been shown to occur in the context of other forms of non-canonical autophagy $[38,40]$.

Regulation of the maturation and degradation of autophagosomes

After their formation, autophagosomes can merge with endocytic compartments (early and late endosomes, multivesicular bodies (MVBs) can merge with autophagosomes) before fusing with the lysosomal compartment [42-44]. The term "amphisome" (from the Greek roots, amphi: both and soma: body) has been coined by Seglen (reviewed in [45]) for the vacuole that results from the fusion of an autophagosome with an endosome. The late stage of autophagy depends on molecules that regulate the maturation of autophagosomes, including their fusion with endosomes and lysosomes, as well as on the acidification of the autophagic compartments, and the recycling of metabolites from the lysosomal compartment (Figure 1). These steps are of a fundamental importance for the flux (defined here as extending from the cargo sequestration step to that of its lysosomal degradation) of material through the autophagic pathway [46]. Any blockade in the maturation of autophagosomes, fusion with the lysosomal compartment, or impairment of the lysosomal function or biogenesis would result in an accumulation of autophagosomes that would inevitably slow down or interrupt the autophagic flux [10,47].

\section{Regulation of maturation}

Rubicon and UVRAG Rubicon and UVRAG (UV irradiation resistance-associated gene) are two Beclin 1-binding proteins that regulate the maturation of autophagosomes and endocytic trafficking [48-50]. It has been suggested that the Beclin 1:hVps34:UVRAG:Rubicon complex down-regulates these trafficking events, whereas the Beclin 1:hVps34:UVRAG complex up-regulates the maturation of autophagosomes and the endocytic trafficking $[49,50]$. Therefore, Beclin 1 regulates both the formation of autophagosomes (via its interaction with Atg14L) and the maturation of autophagosomes (via its interaction with UVRAG and Rubicon).

Rab proteins Colombo and co-workers [51], and Eskelinen and co-workers [52] have shown that Rab7 is required for autophagosome maturation. Autophagosome maturation is dependent on interactions with class $\mathrm{C}$ Vps proteins and UVRAG [53]. This function of UVRAG is independent of its interaction with Beclin 1, and stimulates Rab7 GTPase activity and the fusion of autophagosomes with late endosomes/lysosomes. Interestingly, Rab11 is required for the fusion of autophagosomes and MVBs during starvation-induced autophagy in the erythroleukemic cell line K562 [54]. These findings suggest that specific membrane-bound compartment fusion processes during the maturation of autophagosomes engage different sets of Rab proteins, and possibly associated cohort proteins. Other Rab proteins such as Rab22 and Rab24 have subcellular locations compatible with a role in autophagy [55-57].

ESCRT and Hrs The endosomal sorting complex required for transport (ESCRT) mediates the biogenesis of MVB and the sorting of proteins in the endocytic pathway [58]. It has recently been demonstrated that the multisubunit complex ESCRT III is needed for autophagosomes to fuse with MVB and lysosomes to generate amphisomes and autolysosomes, respectively [59-61]. ESCRT III dysfunction associated with the autophagic pathway may have important implications in neurodegenerative diseases (such as frontotemporal dementia and amyotrophic lateral sclerosis) [59, 60]. The Hrs protein (hepatocyte growth factor-regulated tyrosine kinase substrate) plays a major role in endosomal sorting upstream of ESCRT complexes [58]. Hrs contains a FYVE 
domain that binds specifically to PtdIns3P, and facilitates the maturation of autophagosomes [62]. This raises the intriguing possibility that PtdIns3P may be required for both the formation of the autophagosome and its maturation. However, the precise role of ESCRT proteins in autophagy remains to be elucidated. It is currently impossible to rule out the possibility that these proteins could be involved in the closing of autophagosomes (reviewed in [63]).

SNAREs Soluble $N$-ethylmaleimide-sensitive factor attachment protein receptors (SNAREs) are basic elements in intracellular membrane fusion $[64,65]$. In yeast the vacuolar t-SNAREs Vam3 [66] and Vti1 [67] are needed for complete fusion to occur between the autophagosome and the vacuole (the name given to the lysosome in yeast) in $S$. cerevisiae. The mammalian homologue of Vti1, Vti1b, may be involved in a late stage of autophagy, because the maturation of autophagic vacuoles is delayed in hepatocytes isolated from mice in which Vti1b has been deleted [68]. More recently, Colombo and colleagues [69] have reported that VAMP3 and VAMP7, two v-SNAREs, control the fusion between autophagosomes and MVB and fusion of amphisomes with lysosomes, respectively.

Endo/lysosomal membrane proteins LAMPs (lysosomal-associated membrane proteins) are a family of heavily glycosylated, endo/lysosomal transmembrane proteins [70]. Autophagic degradation has been shown to be impaired in hepatocytes isolated from LAMP-2-deficient mice [71]. However, no defect in autophagy was observed in LAMP-2-deficient mouse fibroblasts [72]. A blockade in the later stage of autophagy only occurs in fibroblasts that are deficient for both LAMP-1 and LAMP2. The differences in the autophagic activity observed between hepatocytes and fibroblasts may be responsible for the cell type-specific effects of LAMP-1 and LAMP2 depletion [10].

DRAM DRAM (Damage-regulated autophagy modulator) encodes a 238 -amino-acid protein that is conserved through evolution, but has no ortholog in yeast [73]. DRAM is a direct target of $\mathrm{p} 53$. The protein is a multispanning transmembrane protein present in the lysosome. DRAM may regulate late stages of autophagy, but, surprisingly, it also controls the formation of autophagosomes [73]. This suggests the possibility of a new paradigm in which feedback signals from the lysosomes control the early stages of autophagy.

Microtubules Destabilization of microtubules by either vinblastin [74] or nocodazole [75] blocks the maturation of autophagosomes, whereas their stabilization by taxol increases the fusion between autophagic vacuoles and lysosomes [76]. More recent findings have confirmed the role of microtubules in the fusion with the acidic compartment [77-79]. Autophagosomes move bidirectionally along microtubules. Their centripetal movement is dependent on the dynein motor [80, 81]. Two types of fusion have been documented [77]: 1, complete fusion of the autophagosome with the lysosome; 2 , transfer of material from the autophagosome to the lysosomal compartment following a kiss-and-run fusion process in which two separate vesicles are maintained [49]. However, fusion with lysosomes can be microtubule-independent during starvation-induced autophagy when autophagosomes are formed in the vicinity of lysosomes [82].

\section{Acidification and degradation}

ATPases Vacuolar ATPases (v-ATPases) are ubiquitous, multi-subunit proteins located in the acidic compartment [83]. Inhibition of the activity of v-ATPase by bafilomycin A1 or concanamycin A blocks the lysosomal pumping of $\mathrm{H}+$ and consequently inhibits lysosomal enzymes, which are active at low $\mathrm{pH}$. It has been proposed that bafilomycin A1 blocks the late stages of autophagy by interfering with the fusion of autophagosomes with endosomes and lysosomes [84] or preventing the lysosomal degradation of sequestered material $[82,85]$. Overall, the resulting effect of the inhibition of v-ATPase is to interrupt the autophagic flux as determined by the inhibition of lysosomal degradation of autophagic cargo. Interestingly, it has recently been demonstrated that a deficiency of vacuolar H+-ATPase homolog (VMA21), a chaperone that binds to the $\mathrm{c}^{\prime \prime}$ subunit of the v-ATPase in the ER and that is responsible for X-linked myopathy with excessive autophagy (XMEA), causes an accumulation of autophagic vacuoles and interrupts autophagy flux in striated muscle cells [86].

ATPases associated with various cellular activity proteins (AAA ATPases) are a family of proteins broadly engaged in intracellular membrane fusion [87]. $\mathrm{N}$-ethylmaleimide sensitive factor (NSF) is an AAA ATPase that binds to SNARE complexes and utilizes ATP hydrolysis to disassemble them, thus facilitating SNARE recycling. In yeast mutants lacking sec18 (the yeast homolog of NSF), autophagosomes are formed, but do not fuse with the vacuole [67]. However, we do not know whether the ATPase activity of NSF plays a role in the later stages of autophagy in mammalian cells. Nevertheless, the activity of NSF is attenuated during starvation, which provides a possible explanation for the slow fusion between autophagosomes and lysosomes observed when autophagy 
is induced by starvation [82]. Suppressor of $\mathrm{K}+$ transport growth defect 1 (SKD1-Vps4), another AAA ATPase protein, is required for the maturation of autophagosomes [88] in mammalian cells. Vps4 controls the assembly of ESCRT complexes on the multivesicular membrane, and is involved in autophagosome maturation [61] in Drosophila, and autophagosome fusion with the vacuole in yeast [89].

Degradation and lysosomal efflux By virtue of lysosomal degradation, autophagy contributes to regulating the metabolism of carbohydrates, lipids and proteins [9092]. Like acidification defects in the endo/lysosomal compartment, defects in the transport or expression of lysosomal enzymes induce a blockade of autophagy, which is characterized by an accumulation of autophagic vacuoles $[93,94]$. The final stage of autophagy is the efflux of metabolites generated by the lysosomal degradation of macromolecules into the cytosol (reviewed in [95]). Atg22 has recently been identified as a permease that recycles amino acids from the vacuole in S. cerevisiae [96].

Cytoplasmic and nuclear regulation of mammalian autophagy

Several recent reviews have been dedicated to the regulation of autophagy by signaling pathways [46, 97, 98]. In this section we would like to focus on signaling pathways with identified targets in the molecular machinery of autophagosome formation. We will also discuss on the role of signaling pathways and transcription factors in the regulation of the expression of genes involved in controlling autophagy (Figure 2).

\section{Cytoplasmic regulation}

mTORC1 and mTORC2 Many signals, including growth factors, amino acids, glucose, and energy status, are integrated by the kinase mTOR [99]. The induction of autophagy by the inhibition of TOR under conditions of starvation is conserved from yeast to mammals [100, 101]. The mTOR pathway involves two functional complexes: mTORC1 and mTORC2. Both these complexes are involved in the regulation of autophagy (Figure 2). mTORC1, the rapamycin-sensitive mTORC1, contains the mTOR catalytic subunit, raptor (regulatory associated protein of mTOR, a protein that acts as a scaffold for the mTOR-mediated phosphorylation of mTOR substrates), G $\beta \mathrm{L}$ and PRAS40 (proline-rich Akt substrate of $40 \mathrm{kDa}$ ). The binding of FKBP12 to mTOR inhibits the mTORraptor interaction, suggesting a mechanism for rapamycin-specific inhibition of mTOR signaling [102]. This mTOR-raptor interaction and its regulation by nutrients and/or rapamycin are dependent on G $\beta L$ [103]. A major unanswered question about the stimulation of autophagy during starvation is how amino acids signal to mTOR [104]. It has been suggested that $\mathrm{hVps} 34$ may have a role in the amino acid signaling to mTORC1 $[105,106]$. Thus, it appears that hVps34 acts both as a down-regulator of autophagy (acting as an amino-acid sensor) and as an up-regulator (because it is a component of Beclin 1 complexes) of autophagy. However, recent observations in Drosophila and mammalian cells suggest that Rag GTPases (Ras-related small GTPases) activate TORC1 in response to amino acids by promoting its redistribution to a specific subcellular compartment, which contains the TORC1 activator Rheb (Ras homolog enriched in brain, a GTP-binding protein) $[107,108]$. Moreover, the ratelimiting factor that enables essential amino acids to regulate mTORC1 has been identified as L-glutamine [109]. L-glutamine uptake is regulated by solute carrier family 1, member 5 (SLC1A5). Loss of SLC1A5 function activates autophagy and inhibits cell growth. L-glutamine sensitivity is attributable to SLC7A5/SLC3A2, a bidirectional transporter that regulates the simultaneous efflux of L-glutamine out of cells and the transportation of Lleucine/essential amino acids into cells [109].

The other mTOR complex, mTORC2, which is less sensitive to rapamycin, includes mTOR, rictor (rapamycin-insensitive companion of mTOR), GBL, SIN1 (SAPK-interacting protein 1) and PROTOR (protein observed with rictor) [110]. The mTORC2 complex phosphorylates the $\mathrm{Ser}^{473}$ of $\mathrm{Akt} / \mathrm{PKB}$, thereby contributing to the activation of this important cell-survival kinase [110]. Phosphorylated Akt/PKB down-regulates the activity of the transcription factor Forkhead Box O3 (FoxO3). Interestingly, FoxO3 has been shown to stimulate autophagy in muscle cells by increasing the transcription of several genes involved in autophagy (see below) [111].

Signaling segments acting upstream of mTORC1 and mTORC2 that regulate autophagy have been discussed in recent reviews that the reader can consult for more information $[46,98]$.

mTORC1 substrates and the regulation of autophagy As discussed above, ULK1, Atg13 and FIP200 form a stable complex that signals to the autophagic machinery downstream of mTORC1. Importantly, mTORC1 is incorporated into the ULK1:Atg13:FIP200 complex via ULK1 in a nutrient-dependent manner. mTOR phosphorylates both ULK1 and Atg13. Under starvation conditions or in response to rapamycin treatment, mTORC1 dissociates from the ULK1 complex, resulting in the activation of ULK1. Activated ULK1 autophosphorylates, and also phosphorylates both Atg13 and FIP200 to initi- 


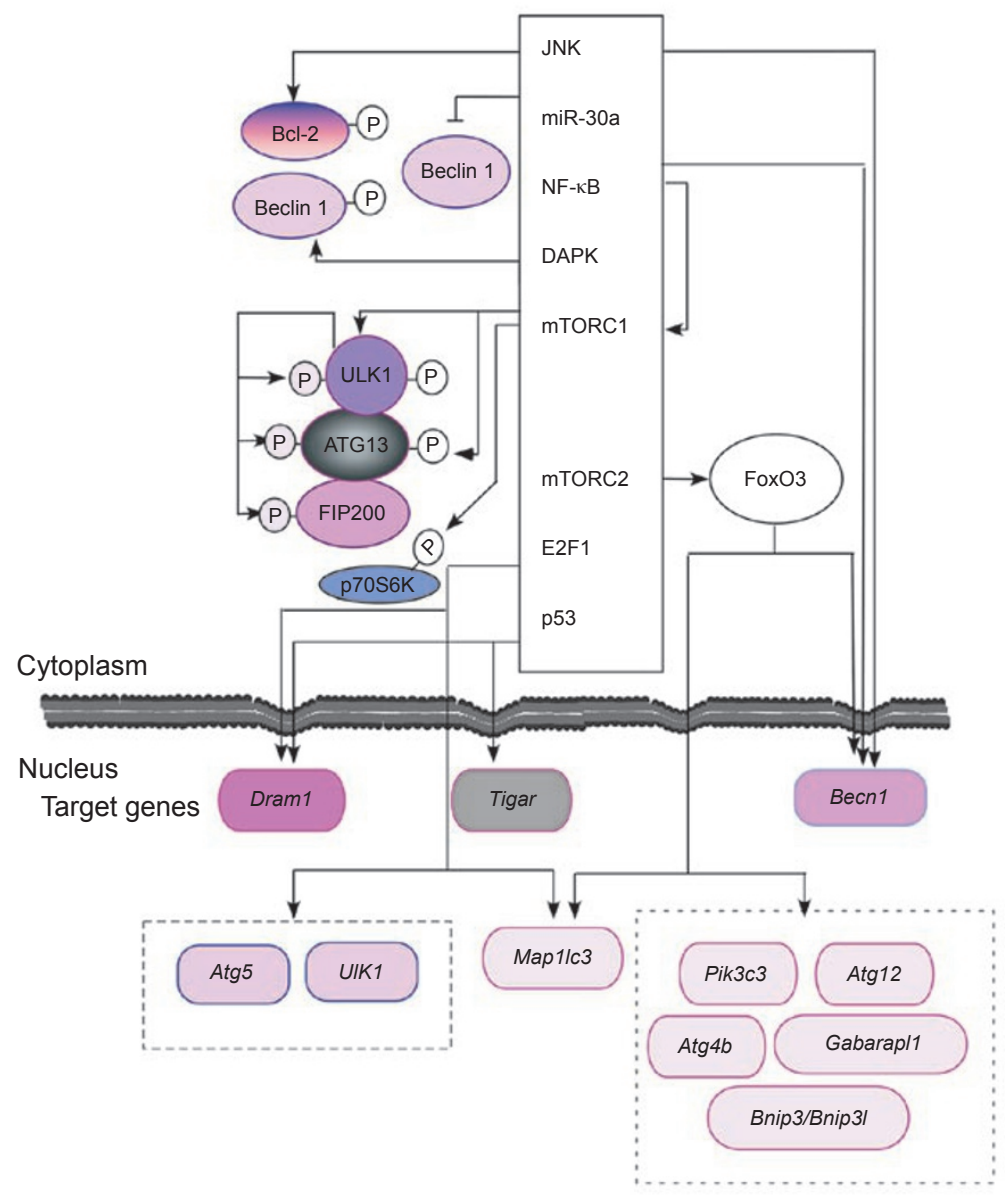

Figure 2 Diagram of the cytoplasmic and nuclear targets of autophagy regulators. JNK phosphorylates Bcl-2, and triggers its release from Beclin 1 in response to various stimuli (such as starvation, ceramide, etc.). In a reciprocal manner, Beclin 1 is phosphorylated by DAPK, which reduces its affinity for $\mathrm{Bcl}-2 / \mathrm{Bcl}-\mathrm{X}_{\mathrm{L}}$. The expression of Beclin 1 is also down-regulated by the microRNA miR-30a. mTORC1, a rapamycin-sensitive mTOR complex, suppresses autophagy by phosphorylating ULK1 and Atg13. In starved cells when mTORC1 is inhibited, the Ser/Thr protein kinase ULK1 is activated, resulting in its autophosphorylation and phosphorylation of Atg13 and FIP200, and the initiation of autophagy. Kinase p70S6K is a substrate of mTORC1 and is involved in the regulation of autophagy. mTORC2, which is less sensitive to rapamycin, phosphorylates Akt/PKB on $\mathrm{Ser}^{473}$. Phosphorylated Akt/PKB down-regulates the activity of the transcription factor FoxO3. Interestingly, FoxO1 and FoxO3 stimulate autophagy by increasing the expression of several Atg genes, such as Map1/c3, Atg12, Gabarap/1 and Bnip3/ Bnip3l. Activation of E2F1 transcription factor has been shown to induce autophagy by upregulating the expression of the autophagy genes Map1/c3, Ulk1, Atg5 and Dram. The transcription factor NF-kB controls the expression of Beclin 1 by interacting with the Becn1 promoter. Similarly, JNK controls the expression of Beclin 1 through c-Jun. Thus, JNK controls autophagy by both cytoplasmic and nuclear effects. It should be mentioned that in some settings inhibiting NF- $\mathrm{KB}$ triggers autophagy. p53, via its nuclear activity, regulates the expression of Dram and Tigar. DRAM promotes autophagy, whereas TIGAR inhibits autophagy. However, when localized in the cytoplasm, p53 inhibits autophagy. Though not shown in the figure, the HIF-1 transcription factor controls the expression of Bnip3/Bnip3l.

ate autophagy [19]. The location of phosphorylation sites, as well as the role played by other members of the ULK family, ULK2 and ULK3, remains to be determined. Once activated, mTORC1 favors cell growth by promoting translation via the phosphorylation of the $70-\mathrm{kDa}$, polypeptide 1 ribosomal protein S6 kinase-1 (p70S6K) and phosphorylation of the inhibitor of translation initia- tion, 4E-BP1. Interestingly, Neufeld and coworkers [112] showed that $\mathrm{p} 70 \mathrm{~S} 6 \mathrm{~K}$ is up-regulated during starvationinduced autophagy in the Drosophila fat body. Mammalian cells probably have a regulatory feedback pathway involving S6K that regulates autophagy [113]. p70S6K is known to phosphorylate and inhibit IRS1 downstream of the insulin receptor (reviewed in [98]). This loop could 
provide a way to regulate the activity of $\mathrm{mTORC} 1$ during starvation-induced autophagy.

Beclin 1:hVps34 complexes As discussed in the preceding sections, the trimer Beclin 1:hVps34:hVps 15 can interact with various different partners to control the formation and maturation of autophagosomes. Recently, the anti-apoptotic protein Bcl-2 and anti-apoptotic members of the Bcl-2 family such as $\mathrm{Bcl}-\mathrm{X}_{\mathrm{L}}$ were shown to inhibit autophagy [114-116]. Bcl-2/Bcl- $\mathrm{X}_{\mathrm{L}}$ binds Beclin 1 through a $\mathrm{BH} 3$ domain that mediates the docking of the latter to the $\mathrm{BH} 3$-binding groove. The constitutive $\mathrm{Bcl}-2 / \mathrm{Bcl}-\mathrm{X}_{\mathrm{L}}$ :Beclin 1 interaction is disrupted by signals that promote autophagy. Importantly, c-Jun N-terminal kinase 1 (JNK-1) phosphorylates three amino acids in the $\mathrm{N}$-terminal loop of Bcl-2 to trigger its release from Beclin 1 [117] in response to starvation or ceramide treatment $[117,118]$. In a reciprocal manner, the $\mathrm{BH} 3$ domain of Beclin 1 can be phosphorylated by death-associated protein kinase (DAPK), which has the effect of reducing its affinity for $\mathrm{Bcl}-\mathrm{X}_{\mathrm{L}}$ [119]. A second mechanism that leads to the dissociation of the complex involves the competitive displacement of the BH3-domain of Beclin 1 from $\mathrm{Bcl}-2 / \mathrm{Bcl}-\mathrm{X}_{\mathrm{L}}$ by other $\mathrm{BH} 3$-containing proteins with proapoptotic properties, such as the $\mathrm{BH} 3$-only member of the Bcl-2 family, the pro-apoptotic member of the Bcl-2 family, Bax, and BH3-mimetics [116, 120]. The role of the hypoxia-inducible BH3-only proteins BNIP3 and BNIP3L in the dissociation of the Beclin 1:Bcl-2 complex will be discussed in the next section. Overall, these findings point to the central role of Beclin 1:hVps34 complexes in the cross-talk between autophagy and apoptosis. Interestingly, a recent study reports that the anti-apoptotic protein FLIP, which blocks the activation of caspase 8 downstream of death receptors, also acts as an anti-autophagy molecule by blocking the formation of LC3-II via its interaction with Atg3 [121].

Inositol 1,4,5-trisphosphate $\left(\mathrm{IP}_{3}\right)$ receptor Autophagy can also be induced via an mTOR-independent pathway by lowering myo- $\mathrm{IP}_{3}$ levels [122]. This effect can be achieved pharmacologically with drugs such as lithium or L-690 330, which disrupt the metabolism of inositol by inhibiting inositol monophosphatase. Rubinsztein and coworkers [123] found that L-type $\mathrm{Ca}^{2+}$ channel antagonists, the $\mathrm{K}_{\text {ATP }}^{+}$channel opener, and $\mathrm{G}_{\mathrm{i}}$ signaling activators all induce autophagy. These drugs reveal a cyclical mTOR-independent pathway regulating autophagy, in which cAMP regulates IP3 levels, influencing calpain activity, which completes the cycle by cleaving and activating $\mathrm{G}_{\mathrm{s} \alpha}$, which in turn regulates cAMP levels. These data also suggest that insults that elevate intracytosolic $\mathrm{Ca}^{2+}$ (such as excitotoxicity) inhibit autophagy, thus retarding the clearance of aggregate-prone proteins. Both genetic and pharmacological inhibition of the $\mathrm{IP}_{3}$ receptor $\left(\mathrm{IP}_{3} \mathrm{R}\right)$ strongly stimulates autophagy. Kroemer and coworkers [124] have shown that the $\mathrm{IP}_{3} \mathrm{R}$ antagonist xestospongin $\mathrm{B}$ induces autophagy by disrupting a molecular complex formed between the $\mathrm{IP}_{3} \mathrm{R}$ and Beclin 1 , an interaction that is regulated by $\mathrm{Bcl}-2$. The $\mathrm{IP}_{3} \mathrm{R}$ is known to be located in the membranes of the ER, as well as in ER-mitochondrial contact sites, and $\mathrm{IP}_{3} \mathrm{R}$ blockade triggers the autophagy of both ER and mitochondria, as observed in starvation-induced autophagy. ER stressors, such as tunicamycin and thapsigargin, also induce autophagy of the ER and, to a lesser extent, of mitochondria. Autophagy triggered by starvation or $\mathrm{IP}_{3} \mathrm{R}$ blockade is inhibited by Bcl-2, and Bcl- $\mathrm{X}_{\mathrm{L}}$ located at the ER, but not at the mitochondrial outer membrane $[114,124]$. In contrast, ER stress-induced autophagy is not inhibited by Bcl-2 or $\mathrm{Bcl}-\mathrm{X}_{\mathrm{L}}$. Autophagy promoted by $\mathrm{IP}_{3} \mathrm{R}$ inhibition cannot be attributed to a modulation of steady-state $\mathrm{Ca}^{2+}$ levels in the ER or in the cytosol [124].

Other cytoplasmic autophagy regulation mechanisms The function of Atg proteins in autophagy can be regulated not only by protein-protein interactions and phosphorylation, but also by oxidation, acetylation, and proteolytic cleavage. Elazar and colleagues [125] have reported that oxidation of a cysteine residue near the catalytic site of Atg4A and Atg4B is required during starvation-induced autophagy. During starvation, the deacetylation of Atg5, Atg7, LC3, and Atg12 is important to stimulate autophagy. The acetylation is dependent on the activity of p300 [126], and the deacetylation is probably under the control of the histone deacetylase sirtuin 1 [127]. Atg5, Atg7, and Beclin 1 are substrates for calpains [128-130], and $A \operatorname{tg} 4 \mathrm{D}$ and Beclin 1 are substrates for caspases [120, 131, 132]. The cleavage of Beclin 1 by caspase 3 and that of Atg5 by calpain 1 inhibit autophagy [120, 130]. The cleavage of Atg proteins by caspases and calpains has been proposed as a possible additional mechanism modulating autophagy. Interestingly, the truncated form of Atg5 generated by calpain 1 cleavage is translocated into the mitochondria and induces apoptosis [128].

\section{Nuclear regulation of autophagy}

JNK/c-Jun The sphingolipid ceramides have been shown to increase the expression of Beclin 1 in human cancer cell lines [133]. In cancer cell lines exposed to ceramide, Li et al. have observed activation of JNK and increased phosphorylation of c-Jun [134]. They also showed that c-Jun controls the transcription of Becnl (we have adopted this nomenclature for the gene encod- 
ing Beclin 1), and the induction of autophagic cell death in response to ceramide. Activation of JNK, resulting in the upregulation of Beclin 1 expression, has also been reported in the autophagic cell death of human colon cancer cells induced by the stimulation of the human death receptor 5 [135].

NF-кB The NF- $\kappa$ B transcription factor, which plays a plethoric role in inflammation, immunity and cancer [136], has also been implicated in regulating autophagy. A conserved NF- $\kappa B$ binding site has recently been unveiled in the promoter of the murine and human gene that encodes Beclin 1 [137]. The authors have shown that p65/RelA, a member of the NF- $\kappa$ B family, up-regulates the expression of Beclin 1 and stimulates autophagy in several cellular systems. Autophagy stimulation has also been observed after the activation of NF- $\mathrm{KB}$ during the heat shock response [138]. However, in contrast to this stimulatory role of $\mathrm{NF}-\mathrm{\kappa B}$ in the regulation of autophagy, the inhibition of NF- $\kappa \mathrm{B}$ favors TNF $\alpha$-dependent and starvation-dependent autophagy [139, 140]. Moreover, Schlottmann et al. reported that activation of NF- $\mathrm{kB}$ prevents autophagy in macrophages by down-regulating the expression of Atg5 and Beclin 1 [141].

E2F1 E2F transcription factors are known to be involved in cellular proliferation, but also in DNA repair, differentiation and development [142]. E2F1 has been shown to bind to the promoter of Becnl, although an effect of $\mathrm{E} 2 \mathrm{~F} 1$ on Beclin 1 expression remains to be demonstrated [143]. More recently, activation of E2F1 has been shown to induce autophagy by up-regulating the expression of the autophagy genes Map1lc3, Ulk1, Atg5 and Dram (we have adopted the nomenclature Mapllc3 for the gene encoding LC3) [144]. The E2F1-mediated induction of Map1lc3, Ulk1 and Dram is direct (through interaction with the promoter), whereas the up-regulation of the expression of Atg5 is indirect.

HIF-1 HIF-1 (hypoxia-inducible factor-1) is a transcription factor, which regulates the transcription of hundreds of genes in response to hypoxia [145]. Recently, Zhang et al. [146] demonstrated that hypoxia induced mitochondrial autophagy via HIF-1-mediated induction of Bnip3. In a similar way, Bellot et al. [147] have shown that hypoxia-induced autophagy is mediated by HIF-1, which induces the expression of BNIP3 and BNIP3L. BNIP3 and BNIP3L play important roles in the induction of autophagy by disrupting the interaction of Beclin 1 with Bcl-2 via their BH3 domain. HIF-1 could also regulate the expression of Beclin 1 and Atg5, probably indirectly, although according to a recent report the silencing of HIF-1 in cultured chondrocytes was associated with a reduced level of Beclin 1 [148].

FoxO proteins Three members of the FoxO family of transcription factors, FoxO1, FoxO3, and FoxO4, are regulated by Akt phosphorylation in response to growth factor and insulin stimulation. FoxO proteins are phosphorylated by Akt, which renders them inactive in the presence of growth factors. When Akt is repressed, FoxO proteins are translocated into the nucleus, bind to DNA, and transactivate their target genes [149]. Several studies of protein degradation during muscle atrophy show that FoxO3 can induce the expression of multiple autophagy genes, including Map1lc3, Atg12, Becn1, Atg4b, Ulk1, $P i k 3 c 3$ (we have adopted the nomenclature $P i k 3 c 3$ for the gene encoding hVps34), Bnip3/Bnip3l, and Gabarapl1 [111, 150], and then upregulates autophagy. FoxO3 can bind directly to the promoter region of some of these genes, such as Map1lc3, Atg12, Gabarapl1, and Bnip3/ Bnip 3l. Expression of a constitutive form of FoxO3 induces autophagy in adult mouse skeletal muscle. Recently, another member of the FoxO protein family, FoxO1, has been shown to regulate the expression of key autophagy genes Pik3c3, Atg12, and Gabarapl1 in hepatocytes in an insulin-dependent manner [151].

p53 p53 is a pivotal factor involved in regulating cell death and survival, and in regulating metabolism [152]. When p53 is activated by cellular stress, p53 accumulates in the cell nucleus, where it transactivates several autophagy-modulating genes including Dram and Tigar (TP53-induced glycolysis and apoptosis regulator). DRAM stimulates the accumulation of autophagosomes, probably by regulating autophagosome-lysosome fusion to generate autophagolysosomes [73]. TIGAR, through its fructose 2,6-bisphosphatase function, can modulate the glycolytic pathway and indirectly contribute to the fall in the intracellular level of ROS [153]. Recently, the same group showed that TIGAR can also modulate the intracellular ROS level in response to nutrient starvation or metabolic stress, and consequently inhibit autophagy via an mTOR-independent pathway [154]. Hence, while DRAM and TIGAR are both transactivated by $\mathrm{p} 53$, DRAM promotes autophagy whereas TIGAR inhibits autophagy. The complexity of the autophagic response to p53 is further increased by the ability of cytoplasmic p53 to limit autophagy [155].

Other regulators of Atg gene expression Recently, the phosphorylation of eIF $2 \alpha$ by PERK has been shown to be essential for the conversion of LC3-I to LC3-II during ER stress induced by polyQ72 or the dysferlin L1341P 
mutant $[156,157]$. In polyQ72-loaded mammalian cells, the phosphorylation of eIF $2 \alpha$ up-regulates the expression of Atg12 [157]. During the unfolded protein response, triggered by hypoxia, the transcription factors ATF4 and CHOP, which are regulated by PERK, increase the expression of Map 1lc3b and Atg5, respectively [158]. Glyceraldehyde-3-phosphate dehydrogenase, a multifunctional enzyme known to play a role in glycolysis as well as having other less well-understood roles such as transcriptional coactivation, has also been shown to upregulate the transcription of $\operatorname{Atg} 12$ to protect cells against caspase-independent cell death [159].

Beclin 1 is one of the essential components involved in autophagosome formation, and its level usually increases during autophagy. For example, in HBV (hepatitis $B$ virus)-infected hepatocytes, the HBV x protein increases autophagy by up-regulating the expression of Beclin 1 [160]. In human monocytes and human myeloid leukemia cells, vitamin D3 has been shown to induce autophagy by up-regulating both Beclin 1 and Atg5 [161, 162]. The transcription factor implicated has not been identified, but it has been shown that in human monocytes the effect of Vitamin D3 is mediated via cathelicidin.

Very recently, Zhu et al. [163] observed for the first time the regulation of autophagy by miRNA. They showed that miR-30a targets Beclin 1 mRNA and downregulates the expression of Beclin 1.

\section{Conclusion}

There is now growing evidence to support the idea that autophagy can be regulated physiologically at several different levels: 1, signaling pathways acting upstream of the autophagy machinery; 2 , the formation of autophagosomes; 3 , the maturation of autophagosomes and their fusion with lysosomes [164]. The existence of these different levels of autophagy regulation means that there are many different ways in which autophagy can be modulated by compounds relevant to clinical interventions [165]. Moreover, the structural biology of Atg proteins is an expanding area of research that should not only reveal the mechanism of action of these proteins, but also guide the design of drugs intended to modulate their activity [166].

\section{Acknowledgments}

Work in P Codogno's laboratory is supported by institutional funding from the Institut National de la Santé et de la Recherche Médicale (INSERM), from Paris-Sud 11 University, grants from the Institut National du Cancer (INCa)-Association pour la Recherche sur le Cancer (ARC) and Agence Nationale de la Recher- che (ANR) to AE.

\section{References}

1 Klionsky DJ. Autophagy: from phenomenology to molecular understanding in less than a decade. Nat Rev Mol Cell Biol 2007; 8:931-937.

2 Kuma A, Hatano M, Matsui M, et al. The role of autophagy during the early neonatal starvation period. Nature 2004; 432:1032-1036.

3 Rubinsztein DC. The roles of intracellular protein-degradation pathways in neurodegeneration. Nature 2006; 443:780786.

4 Virgin HW, Levine B. Autophagy genes in immunity. Nat Immunol 2009; 10:461-470.

5 Mizushima N, Levine B, Cuervo AM, Klionsky DJ. Autophagy fights disease through cellular self-digestion. Nature 2008; 451:1069-1075.

6 Eisenberg-Lerner A, Bialik S, Simon HU, Kimchi A. Life and death partners: apoptosis, autophagy and the cross-talk between them. Cell Death Differ 2009; 16:966-975.

7 Kroemer G, Levine B. Autophagic cell death: the story of a misnomer. Nat Rev Mol Cell Biol 2008; 9:1004-1010.

8 Scarlatti F, Granata R, Meijer AJ, Codogno P. Does autophagy have a license to kill mammalian cells? Cell Death Differ 2009; 16:12-20.

9 Seglen PO, Gordon PB, Holen I. Non-selective autophagy. Semin Cell Biol 1990; 1:441-448.

10 Eskelinen EL. Maturation of autophagic vacuoles in mammalian cells. Autophagy 2005; 1:1-10.

11 Fader CM, Colombo MI. Autophagy and multivesicular bodies: two closely related partners. Cell Death Differ 2009; 16:70-78.

12 Simonsen A, Tooze SA. Coordination of membrane events during autophagy by multiple class III PI3-kinase complexes. J Cell Biol 2009; 186:773-782.

13 Nakatogawa H, Suzuki K, Kamada Y, Ohsumi Y. Dynamics and diversity in autophagy mechanisms: lessons from yeast. Nat Rev Mol Cell Biol 2009; 10:458-467.

14 Axe EL, Walker SA, Manifava M, et al. Autophagosome formation from membrane compartments enriched in phosphatidylinositol 3-phosphate and dynamically connected to the endoplasmic reticulum. J Cell Biol 2008; 182:685-701.

15 Hayashi-Nishino M, Fujita N, Noda T, Yamaguchi A, Yoshimori T, Yamamoto A. A subdomain of the endoplasmic reticulum forms a cradle for autophagosome formation. Nat Cell Biol 2009; 11:1433-1437.

16 Ylä-Anttila P, Vihinen H, Jokitalo E, Eskelinen EL. 3D tomography reveals connections between the phagophore and endoplasmic reticulum. Autophagy 2009; 5:1180-1185.

17 Cheong H, Nair U, Geng J, Klionsky DJ. The Atg1 kinase complex is involved in the regulation of protein recruitment to initiate sequestering vesicle formation for nonspecific autophagy in Saccharomyces cerevisiae. Mol Biol Cell 2008; 19:668-681.

18 Ganley IG, Lam du H, Wang J, Ding X, Chen S, Jiang X. ULK1.ATG13.FIP200 complex mediates mTOR signaling and is essential for autophagy. $J$ Biol Chem 2009; 284:1229712305 . 
19 Hosokawa N, Hara T, Kaizuka T, et al. Nutrient-dependent mTORC1 association with the ULK1-Atg13-FIP200 complex required for autophagy. Mol Biol Cell 2009; 20:19811991.

20 Jung CH, Jun CB, Ro SH, et al. ULK-Atg13-FIP200 complexes mediate $\mathrm{mTOR}$ signaling to the autophagy machinery. Mol Biol Cell 2009; 20:1992-2003.

21 Hosokawa N, Sasaki T, Iemura SI, Natsume T, Hara T, Mizushima N. Atg101, a novel mammalian autophagy protein interacting with Atg13. Autophagy 2009; 5:973-979.

22 Mercer CA, Kaliappan A, Dennis PB. A novel, human Atg13 binding protein, Atg101, interacts with ULK1 and is essential for macroautophagy. Autophagy 2009; 5:649-662.

23 Itakura E, Kishi C, Inoue K, Mizushima N. Beclin 1 forms two distinct phosphatidylinositol 3-kinase complexes with mammalian Atg14 and UVRAG. Mol Biol Cell 2008; 19:5360-5372.

24 Sun Q, Fan W, Chen K, Ding X, Chen S, Zhong Q. Identification of Barkor as a mammalian autophagy-specific factor for Beclin 1 and class III phosphatidylinositol 3-kinase. Proc Natl Acad Sci USA 2008; 105:19211-19216.

25 Cecconi F, Levine B. The role of autophagy in mammalian development: cell makeover rather than cell death. Dev Cell 2008; 15:344-357.

26 Pattingre S, Levine B. Bcl-2 inhibition of autophagy: a new route to cancer? Cancer Res 2006; 66:2885-2888.

27 Vergne I, Roberts E, Elmaoued RA, et al. Control of autophagy initiation by phosphoinositide 3-phosphatase jumpy. EMBO J 2009; 28:2244-2258.

28 Proikas-Cezanne T, Waddell S, Gaugel A, Frickey T, Lupas A, Nordheim A. WIPI-1alpha (WIPI49), a member of the novel 7-bladed WIPI protein family, is aberrantly expressed in human cancer and is linked to starvation-induced autophagy. Oncogene 2004; 23:9314-9325.

29 Young AR, Chan EY, Hu XW, et al. Starvation and ULK1dependent cycling of mammalian Atg9 between the TGN and endosomes. J Cell Sci 2006; 119:3888-3900.

30 Webber JL, Tooze SA. Coordinated regulation of autophagy by $\mathrm{p} 38$ alpha MAPK through mAtg9 and p38IP. EMBO J 2010; 29:27-40.

31 Longatti A, Tooze SA. Vesicular trafficking and autophagosome formation. Cell Death Differ 2009; 16:956-965.

32 Kabeya Y, Mizushima N, Ueno T, et al. LC3, a mammalian homologue of yeast Apg8p, is localized in autophagosome membranes after processing. EMBO J 2000; 19:5720-5728.

33 Mizushima N, Kuma A, Kobayashi Y, et al. Mouse Apg16L, a novel WD-repeat protein, targets to the autophagic isolation membrane with the Apg12-Apg5 conjugate. J Cell Sci 2003; 116:1679-1688.

34 Mizushima N, Sugita H, Yoshimori T, Ohsumi Y. A new protein conjugation system in human. The counterpart of the yeast Apg12p conjugation system essential for autophagy. $J$ Biol Chem 1998; 273:33889-33892.

35 Fujita N, Itoh T, Omori H, Fukuda M, Noda T, Yoshimori T. The Atg16L complex specifies the site of LC3 lipidation for membrane biogenesis in autophagy. Mol Biol Cell 2008; 19:2092-2100.

36 Itoh T, Fujita N, Kanno E, Yamamoto A, Yoshimori T, Fukuda M. Golgi-resident small GTPase Rab33B interacts with
Atg16L and modulates autophagosome formation. Mol Biol Cell 2008; 19:2916-2925.

37 Ravikumar B, Imarisio S, Sarkar S, O'Kane CJ, Rubinsztein DC. Rab5 modulates aggregation and toxicity of mutant huntingtin through macroautophagy in cell and fly models of Huntington disease. J Cell Sci 2008; 121:1649-1660.

38 Nishida Y, Arakawa S, Fujitani K, et al. Discovery of Atg5/ Atg7-independent alternative macroautophagy. Nature 2009; 461:654-658.

39 Mestre MB, Fader CM, Sola C, Colombo MI. a-Hemolysin is required for the activation of the autophagic pathway in Staphylococcus aureus-infected cells. Autophagy 2010; 6:110-125.

40 Scarlatti F, Maffei R, Beau I, Codogno P, Ghidoni R. Role of non-canonical Beclin 1-independent autophagy in cell death induced by resveratrol in human breast cancer cells. Cell Death Differ 2008; 15:1318-1329.

41 Zhu JH, Horbinski C, Guo F, Watkins S, Uchiyama Y, Chu CT. Regulation of autophagy by extracellular signal-regulated protein kinases during 1-methyl-4-phenylpyridiniuminduced cell death. Am J Pathol 2007; 170:75-86.

42 Liou W, Geuze HJ, Geelen MJ, Slot JW. The autophagic and endocytic pathways converge at the nascent autophagic vacuoles. J Cell Biol 1997; 136:61-70.

43 Razi M, Chan EY, Tooze SA. Early endosomes and endosomal coatomer are required for autophagy. J Cell Biol 2009; 185:305-321.

44 Stromhaug PE, Seglen PO. Evidence for acidity of prelysosomal autophagic/endocytic vacuoles (amphisomes). Biochem J 1993; 291:115-121.

45 Fengsrud M, Lunde Sneve M, Øverbye A, Seglen PO. Structural aspects of mammalian autophagy. In: Klionsky DJ, ed. Autophagy. Georgetown, TX: Landes Bioscience, 2004:1125.

46 Codogno P, Meijer AJ. Autophagy and signaling: their role in cell survival and cell death. Cell Death Differ 2005; 12 Suppl 2:1509-1518.

47 Rubinsztein DC, Cuervo AM, Ravikumar B, et al. In search of an "autophagomometer". Autophagy 2009; 5:585-589.

48 Liang C, Feng P, Ku B, et al. Autophagic and tumour suppressor activity of a novel Beclin1-binding protein UVRAG. Nat Cell Biol 2006; 8:688-699.

49 Matsunaga K, Saitoh T, Tabata K, et al. Two Beclin 1-binding proteins, Atg14L and Rubicon, reciprocally regulate autophagy at different stages. Nat Cell Biol 2009; 11:385-396.

50 Zhong Y, Wang QJ, Li X, et al. Distinct regulation of autophagic activity by Atg14L and Rubicon associated with Beclin 1-phosphatidylinositol-3-kinase complex. Nat Cell Biol 2009; 11:468-476.

51 Gutierrez MG, Munafo DB, Beron W, Colombo MI. Rab7 is required for the normal progression of the autophagic pathway in mammalian cells. J Cell Sci 2004; 117:2687-2697.

52 Jager S, Bucci C, Tanida I, et al. Role for Rab7 in maturation of late autophagic vacuoles. J Cell Sci 2004; 117:4837-4848.

53 Liang C, Lee JS, Inn KS, et al. Beclin1-binding UVRAG targets the class $\mathrm{C}$ Vps complex to coordinate autophagosome maturation and endocytic trafficking. Nat Cell Biol 2008; 10:776-787.

54 Fader CM, Sanchez D, Furlan M, Colombo MI. Induction 
of autophagy promotes fusion of multivesicular bodies with autophagic vacuoles in K562 cells. Traffic 2008; 9:230-250.

55 Mesa R, Salomon C, Roggero M, Stahl PD, Mayorga LS. Rab22a affects the morphology and function of the endocytic pathway. J Cell Sci 2001; 114:4041-4049.

56 Egami Y, Kiryu-Seo S, Yoshimori T, Kiyama H. Induced expressions of Rab24 GTPase and LC3 in nerve-injured motor neurons. Biochem Biophys Res Commun 2005; 337:12061213.

57 Olkkonen VM, Dupree P, Killisch I, Lutcke A, Zerial M, Simons K. Molecular cloning and subcellular localization of three GTP-binding proteins of the rab subfamily. J Cell Sci 1993; 106:1249-1261.

58 Raiborg C, Stenmark H. The ESCRT machinery in endosomal sorting of ubiquitylated membrane proteins. Nature 2009; 458:445-452.

59 Filimonenko M, Stuffers S, Raiborg C, et al. Functional multivesicular bodies are required for autophagic clearance of protein aggregates associated with neurodegenerative disease. J Cell Biol 2007; 179:485-500.

60 Lee JA, Beigneux A, Ahmad ST, Young SG, Gao FB. ESCRT-III dysfunction causes autophagosome accumulation and neurodegeneration. Curr Biol 2007; 17:1561-1567.

61 Rusten TE, Vaccari T, Lindmo K, et al. ESCRTs and Fab1 regulate distinct steps of autophagy. Curr Biol 2007; 17:1817-1825.

62 Tamai K, Tanaka N, Nara A, et al. Role of Hrs in maturation of autophagosomes in mammalian cells. Biochem Biophys Res Commun 2007; 360:721-727.

63 Rusten TE, Stenmark H. How do ESCRT proteins control autophagy? J Cell Sci 2009; 122:2179-2183.

64 Gurkan C, Koulov AV, Balch WE. An evolutionary perspective on eukaryotic membrane trafficking. Adv Exp Med Biol 2007; 607:73-83.

65 Rothman JE, Wieland FT. Protein sorting by transport vesicles. Science 1996; 272:227-234.

66 Darsow T, Rieder SE, Emr SD. A multispecificity syntaxin homologue, Vam3p, essential for autophagic and biosynthetic protein transport to the vacuole. J Cell Biol 1997; 138:517529.

67 Ishihara N, Hamasaki M, Yokota S, et al. Autophagosome requires specific early Sec proteins for its formation and NSF/ SNARE for vacuolar fusion. Mol Biol Cell 2001; 12:36903702.

68 Atlashkin V, Kreykenbohm V, Eskelinen EL, Wenzel D, Fayyazi A, Fischer von Mollard G. Deletion of the SNARE vtilb in mice results in the loss of a single SNARE partner, syntaxin 8. Mol Cell Biol 2003; 23:5198-5207.

69 Fader CM, Sanchez DG, Mestre MB, Colombo MI. TIVAMP/VAMP7 and VAMP3/cellubrevin: two v-SNARE proteins involved in specific steps of the autophagy/multivesicular body pathways. Biochim Biophys Acta 2009; 1793: 1901-1916.

70 Eskelinen EL, Tanaka Y, Saftig P. At the acidic edge: emerging functions for lysosomal membrane proteins. Trends Cell Biol 2003; 13:137-145.

71 Tanaka Y, Guhde G, Suter A, et al. Accumulation of autophagic vacuoles and cardiomyopathy in LAMP-2-deficient mice. Nature 2000; 406:902-906.
72 Eskelinen EL, Schmidt CK, Neu S, et al. Disturbed cholesterol traffic but normal proteolytic function in LAMP-1/ LAMP-2 double-deficient fibroblasts. Mol Biol Cell 2004; 15:3132-3145.

73 Crighton D, Wilkinson S, O'Prey J, et al. DRAM, a p53induced modulator of autophagy, is critical for apoptosis. Cell 2006; 126:121-134.

74 Høyvik H, Gordon PB, Berg TO, Stromhaug PE, Seglen PO. Inhibition of autophagic-lysosomal delivery and autophagic lactolysis by asparagine. J Cell Biol 1991; 113:1305-1312.

75 Aplin A, Jasionowski T, Tuttle DL, Lenk SE, Dunn WA Jr. Cytoskeletal elements are required for the formation and maturation of autophagic vacuoles. J Cell Physiol 1992; 152:458-466.

$76 \mathrm{Yu}$ QC, Marzella L. Modification of lysosomal proteolysis in mouse liver with taxol. Am J Pathol 1986; 122:553-561.

77 Jahreiss L, Menzies FM, Rubinsztein DC. The itinerary of autophagosomes: from peripheral formation to kiss-and-run fusion with lysosomes. Traffic 2008; 9:574-587.

78 Kochl R, Hu XW, Chan EY, Tooze SA. Microtubules facilitate autophagosome formation and fusion of autophagosomes with endosomes. Traffic 2006; 7:129-145.

79 Webb JL, Ravikumar B, Rubinsztein DC. Microtubule disruption inhibits autophagosome-lysosome fusion: implications for studying the roles of aggresomes in polyglutamine diseases. Int J Biochem Cell Biol 2004; 36:2541-2550.

80 Ravikumar B, Acevedo-Arozena A, Imarisio S, et al. Dynein mutations impair autophagic clearance of aggregate-prone proteins. Nat Genet 2005; 37:771-776.

81 Kimura S, Noda T, Yoshimori T. Dynein-dependent movement of autophagosomes mediates efficient encounters with lysosomes. Cell Struct Funct 2008; 33:109-122.

82 Fass E, Shvets E, Degani I, Hirschberg K, Elazar Z. Microtubules support production of starvation-induced autophagosomes but not their targeting and fusion with lysosomes. $J$ Biol Chem 2006; 281:36303-36316.

83 Forgac M. Vacuolar ATPases: rotary proton pumps in physiology and pathophysiology. Nat Rev Mol Cell Biol 2007; 8:917-929.

84 Yamamoto A, Tagawa Y, Yoshimori T, Moriyama Y, Masaki R, Tashiro Y. Bafilomycin A1 prevents maturation of autophagic vacuoles by inhibiting fusion between autophagosomes and lysosomes in rat hepatoma cell line, H-4-II-E cells. Cell Struct Funct 1998; 23:33-42.

85 Mousavi SA, Kjeken R, Berg TO, Seglen PO, Berg T, Brech A. Effects of inhibitors of the vacuolar proton pump on hepatic heterophagy and autophagy. Biochim Biophys Acta 2001; 1510:243-257.

86 Ramachandran N, Munteanu I, Wang P, et al. VMA21 deficiency causes an autophagic myopathy by compromising V-ATPase activity and lysosomal acidification. Cell 2009; 137:235-246.

87 White SR, Lauring B. AAA + ATPases: achieving diversity of function with conserved machinery. Traffic 2007; 8:16571667.

88 Nara A, Mizushima N, Yamamoto A, Kabeya Y, Ohsumi Y, Yoshimori T. SKD1 AAA ATPase-dependent endosomal transport is involved in autolysosome formation. Cell Struct Funct 2002; 27:29-37. 
89 Shirahama K, Noda T, Ohsumi Y. Mutational analysis of $\mathrm{Csc1/Vps4p:} \mathrm{involvement} \mathrm{of} \mathrm{endosome} \mathrm{in} \mathrm{regulation} \mathrm{of} \mathrm{au-}$ tophagy in yeast. Cell Struct Funct 1997; 22:501-509.

90 Kotoulas OB, Kalamidas SA, Kondomerkos DJ. Glycogen autophagy in glucose homeostasis. Pathol Res Pract 2006; 202:631-638.

91 Kovsan J, Bashan N, Greenberg A, Rudich A. Potential role of autophagy in modulation of lipid metabolism. Am $J$ Physiol Endocrinol Metab 2009 Nov 3. doi:10.1152/ ajpendo.00562.2009

92 Mortimore GE, Pösö AR. Intracellular protein catabolism and its control during nutrient deprivation and supply. Annu Rev Nutr 1987; 7:539-564.

93 Koike M, Shibata M, Waguri S, et al. Participation of autophagy in storage of lysosomes in neurons from mouse models of neuronal ceroid-lipofuscinoses (Batten disease). Am J Pathol 2005; 167:1713-1728.

94 Yogalingam G, Pendergast AM. Abl kinases regulate autophagy by promoting the trafficking and function of lysosomal components. J Biol Chem 2008; 283:35941-35953.

95 Lloyd JB. Metabolite efflux and influx across the lysosome membrane. Subcell Biochem 1996; 27:361-386.

96 Yang Z, Huang J, Geng J, Nair U, Klionsky DJ. Atg22 recycles amino acids to link the degradative and recycling functions of autophagy. Mol Biol Cell 2006; 17:5094-5104.

97 He C, Klionsky DJ. Regulation mechanisms and signaling pathways of autophagy. Annu Rev Genet 2009; 43:67-93.

98 Meijer AJ, Codogno P. Autophagy: regulation and role in disease. Crit Rev Clin Lab Sci 2009; 46:210-240.

99 Kim DH, Sarbassov DD, Ali SM, et al. mTOR interacts with raptor to form a nutrient-sensitive complex that signals to the cell growth machinery. Cell 2002; 110:163-175.

100 Blommaart EF, Luiken JJ, Blommaart PJ, van Woerkom GM, Meijer AJ. Phosphorylation of ribosomal protein S6 is inhibitory for autophagy in isolated rat hepatocytes. $\mathrm{J}$ Biol Chem 1995; 270:2320-2326.

101 Noda T, Ohsumi Y. Tor, a phosphatidylinositol kinase homologue, controls autophagy in yeast. J Biol Chem 1998; 273:3963-3966.

102 Oshiro N, Yoshino K, Hidayat S, et al. Dissociation of raptor from mTOR is a mechanism of rapamycin-induced inhibition of mTOR function. Genes Cells 2004; 9:359-366.

103 Kim DH, Sarbassov DD, Ali DM, et al. G $\beta$ L, a positive regulator of the rapamycin-sensitive pathway required for the nutrient-sensitive interaction between raptor and mTOR. Mol Cell 2003; 11:895-904.

104 Meijer AJ, Dubbelhuis PF. Amino acid signalling and the integration of metabolism. Biochem Biophys Res Commun 2004; 313:397-403.

105 Byfield MP, Murray JT, Backer JM. hVps34 is a nutrient-regulated lipid kinase required for activation of p70 S6 kinase. $J$ Biol Chem 2005; 280:33076-33082.

106 Nobukuni T, Joaquin M, Roccio M, et al. Amino acids mediate $\mathrm{mTOR} /$ raptor signaling through activation of class 3 phosphatidylinositol 3OH-kinase. Proc Natl Acad Sci USA 2005; 102:14238-14243.

107 Kim E, Goraksha-Hicks P, Li L, Neufeld TP, Guan KL. Regulation of TORC1 by Rag GTPases in nutrient response. Nat Cell Biol 2008; 10:935-945.
108 Sancak Y, Peterson TR, Shaul YD, et al. The Rag GTPases bind raptor and mediate amino acid signaling to mTORC1. Science 2008; 320:1496-1501.

109 Nicklin P, Bergman P, Zhang B, et al. Bidirectional transport of amino acids regulates mTOR and autophagy. Cell 2009; 136:521-534.

110 Sarbassov DD, Ali SM, Sengupta S, et al. Prolonged rapamycin treatment inhibits mTORC2 assembly and Akt/PKB. Mol Cell 2006; 22:159-168.

111 Mammucari C, Milan G, Romanello V, et al. FoxO3 controls autophagy in skeletal muscle in vivo. Cell Metab 2007; 6:458-471.

112 Scott RC, Schuldiner O, Neufeld TP. Role and regulation of starvation-induced autophagy in the Drosophila fat body. Dev Cell 2004; 7:167-178.

113 Klionsky DJ, Meijer AJ, Codogno P, Neufeld TP, Scott RC. Autophagy and p70S6 kinase. Autophagy 2005; 1:59-61.

114 Pattingre S, Tassa A, Qu X, et al. Bcl-2 antiapoptotic proteins inhibit Beclin 1-dependent autophagy. Cell 2005; 122:927939.

115 Erlich S, Mizrachy L, Segev O, et al. Differential interactions between Beclin 1 and Bcl-2 family members. Autophagy 2007; 3:561-568.

116 Maiuri MC, Le Toumelin G, Criollo A, et al. Functional and physical interaction between $\mathrm{Bcl}-\mathrm{X}(\mathrm{L})$ and a $\mathrm{BH} 3$-like domain in Beclin-1. EMBO J 2007; 26:2527-2539.

117 Wei Y, Pattingre S, Bassik M, Sinha S, Levine B. JNK1-mediated phosphorylation of $\mathrm{Bcl}-2$ regulates starvation-induced autophagy. Mol Cell 2008; 30:678-688.

118 Pattingre S, Bauvy C, Carpentier S, Levade T, Levine B, Codogno P. Role of JNK1-dependent Bcl-2 phosphorylation in ceramide-induced macroautophagy. J Biol Chem 2009; 284:2719-2728.

119 Zalckvar E, Berissi H, Mizrachy L, et al. DAP-kinasemediated phosphorylation on the $\mathrm{BH} 3$ domain of beclin 1 promotes dissociation of beclin 1 from $\mathrm{Bcl}-\mathrm{XL}$ and induction of autophagy. EMBO Rep 2009; 10:285-292.

120 Luo S, Rubinsztein DC. Apoptosis blocks Beclin 1-dependent autophagosome synthesis: an effect rescued by Bcl-xL. Cell Death Differ 2009; 17:268-277.

121 Lee JS, Li Q, Lee JY, et al. FLIP-mediated autophagy regulation in cell death control. Nat Cell Biol 2009; 11:1355-1362.

122 Sarkar S, Floto RA, Berger Z, et al. Lithium induces autophagy by inhibiting inositol monophosphatase. J Cell Biol 2005; 170:1101-1111.

123 Williams A, Sarkar S, Cuddon P, et al. Novel targets for Huntington's disease in an mTOR-independent autophagy pathway. Nat Chem Biol 2008; 4:295-305.

124 Vicencio JM, Ortiz C, Criollo A, et al. The inositol 1,4,5-trisphosphate receptor regulates autophagy through its interaction with Beclin 1. Cell Death Differ 2009; 16:1006-1017.

125 Scherz-Shouval R, Shvets E, Fass E, Shorer H, Gil L, Elazar Z. Reactive oxygen species are essential for autophagy and specifically regulate the activity of Atg4. EMBO J 2007; 26:1749-1760.

126 Lee IH, Finkel T. Regulation of autophagy by the p300 acetyltransferase. J Biol Chem 2009; 284:6322-6328.

127 Lee IH, Cao L, Mostoslavsky R, et al. A role for the NADdependent deacetylase Sirt1 in the regulation of autophagy. 
Proc Natl Acad Sci USA 2008; 105:3374-3379.

128 Yousefi S, Perozzo R, Schmid I, et al. Calpain-mediated cleavage of Atg5 switches autophagy to apoptosis. Nat Cell Biol 2006; 8:1124-1132.

129 Kim JS, Nitta T, Mohuczy D, et al. Impaired autophagy: a mechanism of mitochondrial dysfunction in anoxic rat hepatocytes. Hepatology 2008; 47:1725-1736.

130 Xia H-G, Zhang L, Chen G, et al. Control of basal autophagy by calpain 1 mediated cleavage of Atg5. Autophagy 2010; 6:61-66.

131 Cho DH, Jo YK, Hwang JJ, Lee YM, Roh SA, Kim JC. Caspase-mediated cleavage of ATG6/Beclin-1 links apoptosis to autophagy in HeLa cells. Cancer Lett 2009; 274:95-100.

132 Betin VM, Lane JD. Caspase cleavage of Atg4D stimulates GABARAP-L1 processing and triggers mitochondrial targeting and apoptosis. J Cell Sci 2009; 122:2554-2566.

133 Scarlatti F, Bauvy C, Ventruti A, et al. Ceramide-mediated macroautophagy involves inhibition of protein kinase B and up-regulation of beclin 1. J Biol Chem 2004; 279:1838418391.

134 Li DD, Wang LL, Deng R, et al. The pivotal role of c-Jun NH2-terminal kinase-mediated Beclin 1 expression during anticancer agents-induced autophagy in cancer cells. Oncogene 2009; 28:886-898.

135 Park KJ, Lee SH, Lee CH, et al. Upregulation of Beclin-1 expression and phosphorylation of Bcl-2 and p53 are involved in the JNK-mediated autophagic cell death. Biochem Biophys Res Commun 2009; 382:726-729.

136 Karin M. Nuclear factor-kappaB in cancer development and progression. Nature 2006; 441:431-436.

137 Copetti T, Bertoli C, Dalla E, Demarchi F, Schneider C. p65/ RelA modulates BECN1 transcription and autophagy. Mol Cell Biol 2009; 29:2594-2608.

138 Nivon M, Richet E, Codogno P, Arrigo AP, Kretz-Remy C. Autophagy activation by NFkappaB is essential for cell survival after heat shock. Autophagy 2009; 5:766-783.

139 Djavaheri-Mergny M, Amelotti M, Mathieu J, et al. NF-kappaB activation represses tumor necrosis factor-alpha-induced autophagy. J Biol Chem 2006; 281:30373-30382.

140 Fabre C, Carvalho G, Tasdemir E, et al. NF-kappaB inhibition sensitizes to starvation-induced cell death in high-risk myelodysplastic syndrome and acute myeloid leukemia. Oncogene 2007; 26:4071-4083.

141 Schlottmann S, Buback F, Stahl B, et al. Prolonged classical NF-kappaB activation prevents autophagy upon E. coli stimulation in vitro: a potential resolving mechanism of inflammation. Mediators Inflamm 2008; 2008:725854.

142 DeGregori J, Johnson DG. Distinct and overlapping roles for E2F family members in transcription, proliferation and apoptosis. Curr Mol Med 2006; 6:739-748.

143 Weinmann AS, Bartley SM, Zhang T, Zhang MQ, Farnham PJ. Use of chromatin immunoprecipitation to clone novel E2F target promoters. Mol Cell Biol 2001; 21:6820-6832.

144 Polager S, Ofir M, Ginsberg D. E2F1 regulates autophagy and the transcription of autophagy genes. Oncogene 2008; 27:4860-4864.

145 Manalo DJ, Rowan A, Lavoie T, et al. Transcriptional regulation of vascular endothelial cell responses to hypoxia by HIF-1. Blood 2005; 105:659-669.
146 Zhang H, Bosch-Marce M, Shimoda LA, et al. Mitochondrial autophagy is an HIF-1-dependent adaptive metabolic response to hypoxia. J Biol Chem 2008; 283:10892-10903.

147 Bellot G, Garcia-Medina R, Gounon P, et al. Hypoxia-induced autophagy is mediated through hypoxia-inducible factor induction of BNIP3 and BNIP3L via their BH3 domains. Mol Cell Biol 2009; 29:2570-2581.

148 Bohensky J, Shapiro IM, Leshinsky S, Terkhorn SP, Adams CS, Srinivas V. HIF-1 regulation of chondrocyte apoptosis: induction of the autophagic pathway. Autophagy 2007; 3:207-214.

149 Salih DA, Brunet A. FoxO transcription factors in the maintenance of cellular homeostasis during aging. Curr Opin Cell Biol 2008; 20:126-136.

150 Zhao J, Brault JJ, Schild A, et al. FoxO3 coordinately activates protein degradation by the autophagic/lysosomal and proteasomal pathways in atrophying muscle cells. Cell $\mathrm{Me}-$ tab 2007; 6:472-483.

151 Liu HY, Han J, Cao SY, et al. Hepatic autophagy is suppressed in the presence of insulin resistance and hyperinsulinemia: inhibition of FoxO1-dependent expression of key autophagy genes by insulin. J Biol Chem 2009; 284:3148431492.

152 Vousden KH, Prives C. Blinded by the light: the growing complexity of p53. Cell 2009; 137:413-431.

153 Bensaad K, Tsuruta A, Selak MA, et al. TIGAR, a p53inducible regulator of glycolysis and apoptosis. Cell 2006; 126:107-120

154 Bensaad K, Cheung EC, Vousden KH. Modulation of intracellular ROS levels by TIGAR controls autophagy. Embo $J$ 2009; 28:3015-3026.

155 Tasdemir E, Maiuri MC, Galluzzi L, et al. Regulation of autophagy by cytoplasmic p53. Nat Cell Biol 2008; 10:676687.

156 Fujita E, Kouroku Y, Isoai A, et al. Two endoplasmic reticulum-associated degradation (ERAD) systems for the novel variant of the mutant dysferlin: ubiquitin/proteasome ERAD(I) and autophagy/lysosome ERAD(II). Hum Mol Genet 2007; 16:618-629.

157 Kouroku Y, Fujita E, Tanida I, et al. ER stress (PERK/eIF2alpha phosphorylation) mediates the polyglutamine-induced LC3 conversion, an essential step for autophagy formation. Cell Death Differ 2007; 14:230-239.

158 Rouschop KM, van den Beucken T, Dubois L, et al. The unfolded protein response protects human tumor cells during hypoxia through regulation of the autophagy genes MAP1LC3B and ATG5. J Clin Invest 2010; 120:127-141.

159 Colell A, Ricci JE, Tait S, et al. GAPDH and autophagy preserve survival after apoptotic cytochrome c release in the absence of caspase activation. Cell 2007; 129:983-997.

160 Tang H, Da L, Mao Y, et al. Hepatitis B virus X protein sensitizes cells to starvation-induced autophagy via up-regulation of beclin 1 expression. Hepatology 2009; 49:60-71.

161 Wang J, Lian H, Zhao Y, Kauss MA, Spindel S. Vitamin D3 induces autophagy of human myeloid leukemia cells. J Biol Chem 2008; 283:25596-25605.

162 Yuk JM, Shin DM, Lee HM, et al. Vitamin D3 induces autophagy in human monocytes/macrophages via cathelicidin. Cell Host Microbe 2009; 6:231-243. 
163 Zhu H, Wu H, Liu X, et al. Regulation of autophagy by a beclin 1-targeted microRNA, miR-30a, in cancer cells. Autophagy 2009; 5:816-823.

164 Esclatine A, Chaumorcel M, Codogno P. Macroautophagy signaling and regulation. Curr Top Microbiol Immunol 2009; 335:33-70.
165 Rubinsztein DC, Gestwicki JE, Murphy LO, Klionsky DJ. Potential therapeutic applications of autophagy. Nat Rev Drug Discov 2007; 6:304-312.

166 Noda NN, Ohsumi Y, Inagaki F. ATG systems from the protein structural point of view. Chem Rev 2009; 109:15871598. 